\title{
Design of a thermoelectric energy source for water pumping applications: A case study in Sharjah, United Arab Emirates
}

\author{
Waleed Obaid ${ }^{1}$, Abdul-Kadir Hamid ${ }^{2}$, Chaouki Ghenai ${ }^{3}$, Mamdouh El Haj Assad ${ }^{4}$ \\ ${ }^{1,2}$ Electrical and Computer Engineering (ECE) Department, University of Sharjah, United Arab Emirates \\ ${ }^{3,4}$ Sustainable and Renewable Energy Engineering (SREE) Department, University of Sharjah, United Arab Emirates
}

\begin{tabular}{l}
\hline Article Info \\
\hline Article history: \\
Received Oct 6, 2020 \\
Revised Mar 29, 2021 \\
Accepted Apr 9, 2021 \\
\hline
\end{tabular}

Keywords:

Renewable energy

Simulink

Thermoelectric modules

Water pumping

Weather forecasting

\begin{abstract}
There are many water pumping power systems that exist nowadays relying on conventional and renewable energy sources such as mechanical windmills, solar photovoltaic (PV) panels, wind turbines, and diesel generators. Few designs utilize thermoelectric modules for the purpose of enhancing the reliability and the performance of the system in order to provide water supply to isolated zones continuously. The use of thermoelectric (TE) modules is increasing due to their reduced prices and the possibility of using them in different applications depending on the required specifications of motors and other connected loads. This paper proposes a renewable energy system design for water pumping applications in Sharjah (Latitude $25.29^{\circ} \mathrm{N}$ and Longitude $55^{\circ} \mathrm{E}$ ), United Arab Emirates. The system involves TE modules for operating the three-phase AC water pumping motor, voltage regulator, voltage boost converter, and three-phase power inverter while considering the changes of temperature values which affect the performance of the thermoelectric generator (TEG) modules. The aim is integrating TEG modules to cover the increasing demand of water in rural areas since rainy days in Sharjah are limited and the temperature is high. The performances of the proposed system will be demonstrated using Simulink simulations for the overall blocks of the proposed system.
\end{abstract}

This is an open access article under the CC BY-SA license.

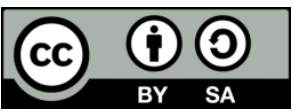

\section{Corresponding Author:}

Waleed Obaid

Electrical and Computer Engineering (ECE) Department

University of Sharjah

Sharjah, United Arab Emirates

Email: U00032590@sharjah.ac.ae

\section{INTRODUCTION}

Sharjah (Latitude $25.29^{\circ} \mathrm{N}$ and Longitude $55^{\circ} \mathrm{E}$ ) is located within the Arabian Desert which lies within the Solar-Belt of the earth. In order to cover the increasing annual demand of energy while considering that location advantage in terms of temperature due to sunny weather, clean and renewable energy sources can be introduced as an alternative solution rather than conventional sources of energy (fuel and diesel) that cause harmful emissions (greenhouse gases effect). Renewable energy systems can be used in wide variety of applications in far and isolated areas as well as rural zones such as water pumping, air conditioning systems, and irrigation [1]. The main challenges that face renewable energy systems are related to weather conditions that can change any time suddenly and unexpectedely during the day such as solar irradiance, temperature, wind speed, and humidity [2]-[6]. In order to solve these problems, battery management and weather forecasting systems can be included in order to predict solar irradiance based on weather condition parameters [7]-[13]. 
Power system designs that involved thermoelectric generator (TEG) modules were investigated in many studies. Some designs in [14], [15] focused on the feasibility of photovoltaic-thermoelectric generator (PV-TEG) hybrid modules by simulation. They discovered the possibility of increasing the efficiency by increasing the TEG's figure of merit value and reducing the internal resistance. A design in [16] investigated the effect of weather conditions on the performance of a hybrid system that involved TEG modules. A design in [17] studied a system that involved TEG modules under the weather conditions of multiple cities in Europe. They concluded that summer weather conditions result in larger power output. A design in [18] relied on weather data of one day in Nanjing, China for performance analysis of a system that involved TEG modules. They found out that the performance is better in terms of efficiency between 11:00 to 13:00.

Water pumping power systems were studied before. An unconcentrated photovoltaic-thermoelectric generator (PV-TEG) hybrid system was designed based on the load requirement of an indoor farm while considering Malaysia's weather conditions in [19]. A wind/PV system was proposed using off-grid wind turbine and solar panels for water pumping systems [20]. A study was presented for a developed assessment methodology for a PV/battery power system. The system utilized the dumbed power for secondary applications such as water pumping [21]. A solar PV water pumping system was proposed using helical pump a deep well in [22]. The system was proposed under the meteorological conditions of Saudi Arabia using four different PV configurations. Hybrid maximum power point tracking (MPPT) controlled solar/wind, solar/wind/diesel, and solar/FC power system designs were proposed for water pumping applications with fuzzy energy management and weather forecasting in [23]-[25]. The primary objective of the proposed system is simulating the TEG energy system to cover the increasing demand of water in isolated areas in Sharjah. The goal is using weather forecasting to obtain temperature values in order to maintain stable operation for the TEG system despite the changes in these values.

\section{RESEARCH METHOD}

A thermoelectric generator (TEG) is a solid-state device. It does not have any moving component. It can be integrated with other applications and systems because of that advantage. TEG is utilized in waste heat recovery applications because of its operation mechanism that converts heat into electricity.

Thermoelectric materials are semiconductors. They produce electric current due to the temperature difference between two different surfaces: the hot side and the cold side. Figure 1 shows an example of a thermoelement that is obtained from conjunction of p-type and n-type semiconductors. Multiple thermoelements can be connected in series. This results in larger obtained voltage. When multiple thermoelements are connected in parallel, the thermal resistance decreases. Figure 2 shows equivalent circuit of the thermoelectric module.

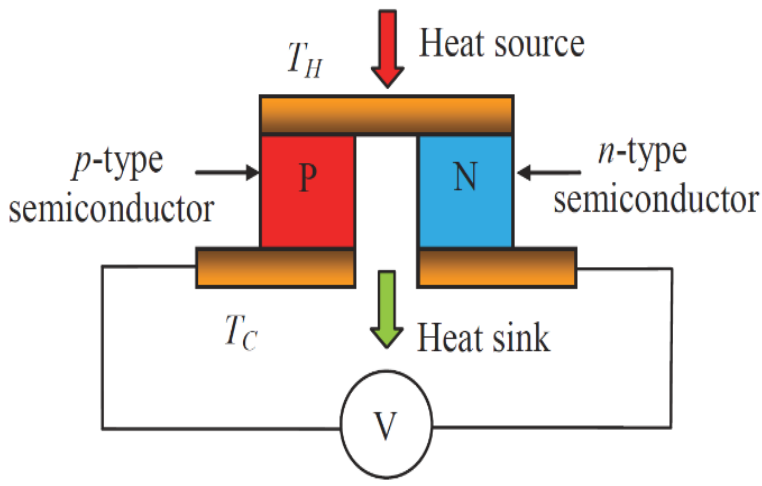

Figure 1. Thermo element components

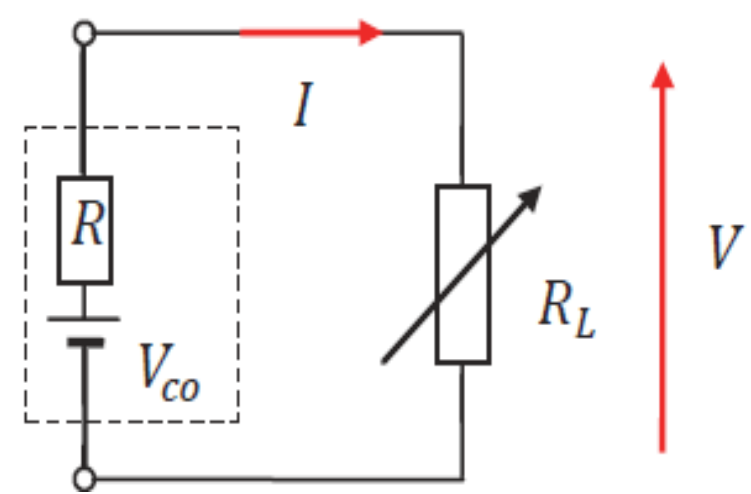

Figure 2. Thermoelectric module equivalent circuit

The absorbed heat by the thermoelectric (TE) module hot side QH and the liberated heat by the cold side QC are being as [26]-[28]:

$$
\begin{aligned}
& Q_{H}=\alpha I T_{H}+k\left(T_{H}-T_{c}\right)-0.5 R I^{2} \\
& Q_{C}=\alpha I T_{C}+k\left(T_{H}-T_{c}\right)-0.5 R I^{2}
\end{aligned}
$$


where $\alpha$ is the Seebeck coefficient, $R$ is the internal resistance, and $k$ represents the thermal conductance. The output power can be obtained using the current $I$ and the voltage $V$ is being as:

$$
P=I V=Q_{H}-Q_{C}=\alpha I\left(T_{H}-T_{c}\right)-R I^{2}
$$

The voltage can be expressed as:

$$
V=\alpha\left(T_{H}-T_{c}\right)-R I
$$

The proposed water pumping power system block diagram is demonstrated in Figure 3 . The system uses the TEG module 1MD10-037-05 which is produced by "RMT" company. The simulation used the parameters of the real TEG module such as $0.027 \mathrm{mV} / \mathrm{K}$ seebeck coefficient. The proposed system has 15 parallel blocks of TEG modules. Each parallel block has 400 TEG modules connected in series. The system involves voltage regulator block in order to obtain $12 \mathrm{~V}$ constant voltage value from the variable TEG DC voltage which changes because of the changes in temperature values throughout the day. The regulator contains three resistors, one operational amplifier, and one transistor. The obtained constant voltage is increased using voltage boost converter block in order to increase the voltage to be close to $380 \mathrm{~V}$ direct current (DC). The voltage boost converter contains an insulated gate bipolar transistor (IGBT), a resistor, an inductor, a diode, and a pulse width modulation (PWM) signal that is connected to the IGBT. The obtained voltage from the boost converter block is converted to three-phase AC voltage using three-phase power inverter block. It contains metal-oxide-semiconductor field-effect transistor (MOSFET) universal bridge and SVPWM generator, the inverter is used to obtain three-phase $380 \mathrm{~V}$ AC from the DC input voltage to power the AC three-phase motor. The obtained three-phase AC voltage is used to power the three-phase electrical water pump AC motor in order to obtain constant speed regardless the changes in temperatures values that affect the TEG modules.

\section{RESULTS AND DISCUSSION}

The Simulink blocks that were used to simulate the proposed water pumping system are shown in the power system block diagram in Figure 3. In order to simulate the performance of the TEG system, the cold side temperature was fixed at 20 Celsius while the hot side temperature was varied according to the measured temperature of a sunny day in Sharjah during summer period (June). Heat sink components can be used for the purpose of fixing the temperature of the TEG cold side. Table 1 shows the cold and hot side temperature values. The used TEG module provides optimum power output values of $0.46 \mathrm{~W}, 0.11 \mathrm{~W}$, and $0.009 \mathrm{~W}$ when the cold side temperature is fixed at 27 Celsius and the hot side temperature values are 85, 55, and 35 Celsius respectively as per the datasheet. The number of TEG modules was chosen based on the average output power that varies between $0.009 \mathrm{~W}$ and $0.11 \mathrm{~W}$ as per the obtained values of temperature. The corresponding open circuit voltage values are $0.93 \mathrm{~V}, 0.44 \mathrm{~V}$, and $0.13 \mathrm{~V}$ respectively while the resistance values in Ohms are $0.47,0.44$, and 0.42 respectively. The selected resistance value was close to $0.44 \mathrm{Ohm}$ in the proposed design according to the information in the datasheet. The dimensions of the TEG module are $13.6 \times 8.6 \times 1.6 \mathrm{~mm}$.

Figures 4 and 5 show the obtained DC current and voltage values of the TEG modules. The corresponding obtained power is shown in Figure 6. The maximum and minimum values of the obtained current are 19.4 A and 15.1 A respectively while the maximum and minimum DC voltage values are $77 \mathrm{~V}$ and $60.5 \mathrm{~V}$ respectively. The maximum and minimum obtained output power from the TEG modules are $920 \mathrm{~W}$ and $1490 \mathrm{~W}$. Table 2 demonstrates the output values of the TEG modules. The maximum output power was obtained at the middle of the day since the temperature is high during afternoon time. The output voltage from the voltage regulator was maintained constant at $12 \mathrm{~V}$ as shown in Figure 7 regardless the changes in temperature values. The voltage was raised using the voltage boost converter block to obtain larger DC voltage value that is close to $380 \mathrm{~V}$ as shown in Figure 8. The raised DC voltage was converted to $380 \mathrm{AC}$ by the power inverter block as shown in Figure 9.

Figures 10 and 11 show the obtained output speed and torque of the three-phase AC motor. The output motor is a $0.75 \mathrm{~kW}$ low pressure three-phase AC motor that has applications in wastewater treatment, water treatment solutions, and pharmaceutical industry. The motor can also be operated at $415 \mathrm{~V}$ and $440 \mathrm{~V}$. The speed value was close to $166 \mathrm{wm}$ while the toque value was close to $11.9 \mathrm{Nm}$. It can be noted that the speed and torque were maintained constant despite the changes in temperature. The novelty of this proposed design is that it relies only on TEG modules for the purpose of delivering constant power to the water pump AC motor to obtain constant speed. The proposed water pumping power system can be used to provide reliable water source to isolated or remote areas in Sharjah since it relies on TEG modules that can operate 
during day and night times based on temperate values. In order to implement the proposed TEG water pumping system, the components in Figure 12 can be used which involve the three-phase water pumping motor, the voltage regulator, the voltage boost converter, the DC to AC power inverter, and the 1MD10-03705 TEG modules. Table 3 demonstrates the cost analysis of the system based on the chosen components and TEG modules.
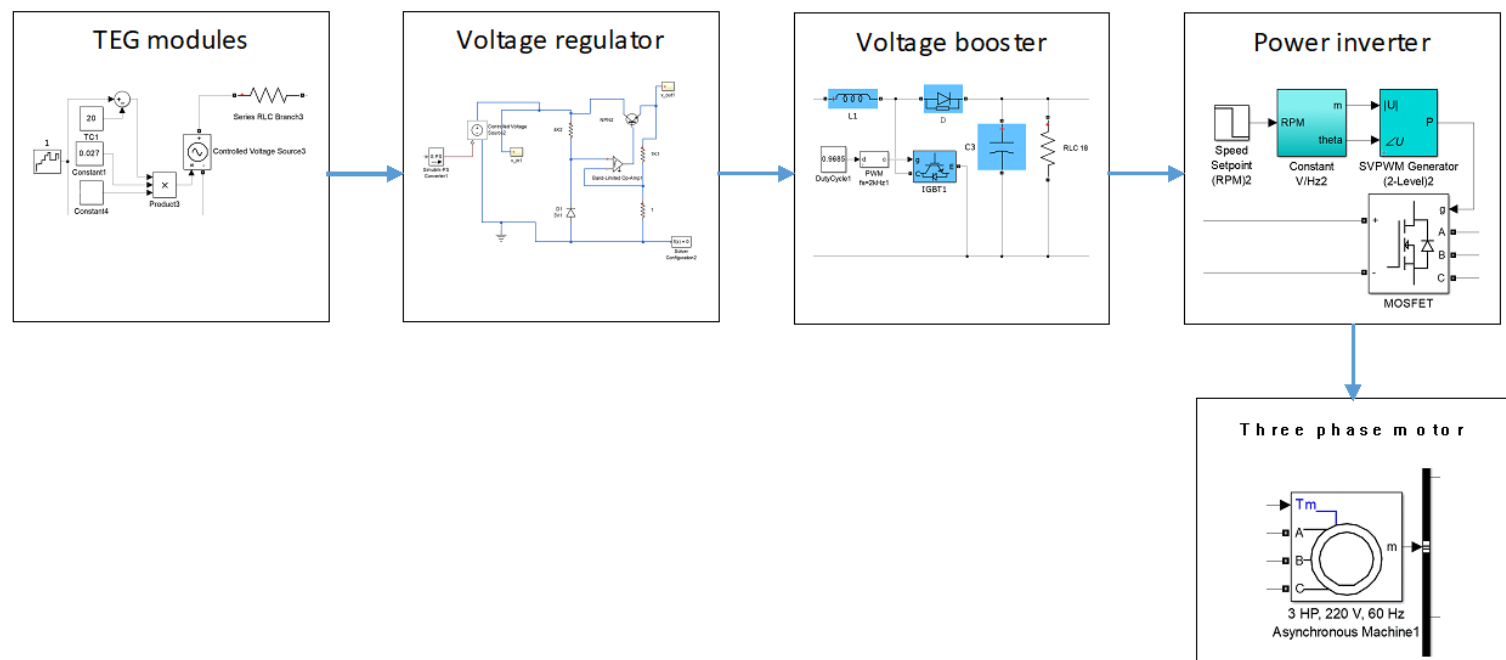

Figure 3. The proposed water pumping system blocks

Table 1. The used temperature values for the TEG hot and cold sides

\begin{tabular}{cc}
\hline TEG hot side temperature in Celsius & TEG cold side temperature in Celsius \\
\hline 40 & 20 \\
44 & 20 \\
44 & 20 \\
45 & 20 \\
46 & 20 \\
48 & 20 \\
45 & 20 \\
45 & 20 \\
47 & 20 \\
46 & 20 \\
\hline
\end{tabular}

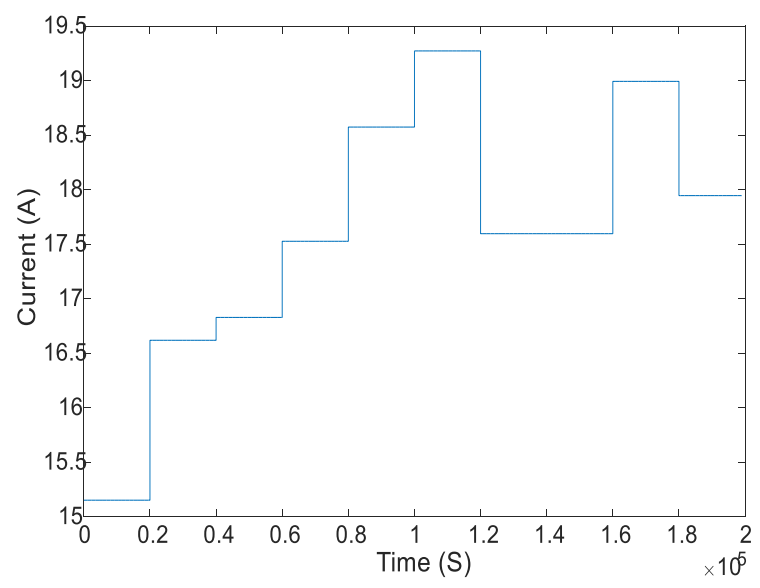

Figure 4. The obtained DC current of the TEG modules

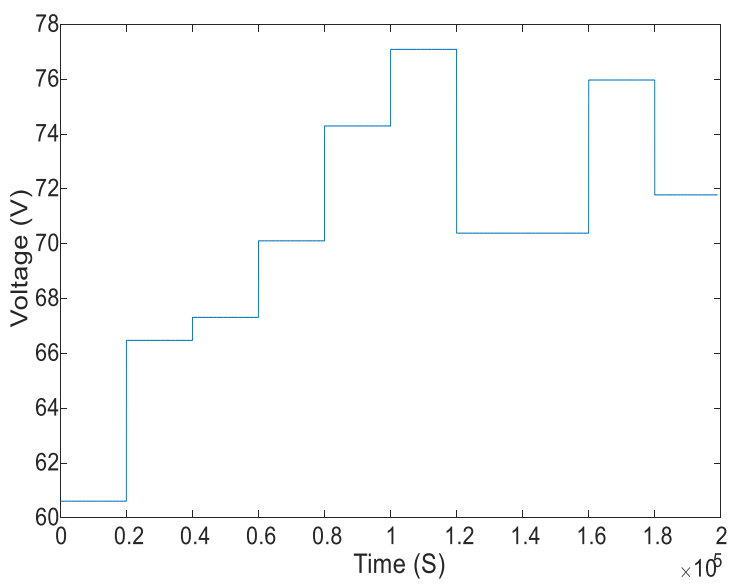

Figure 5. The obtained DC voltage of the TEG modules 


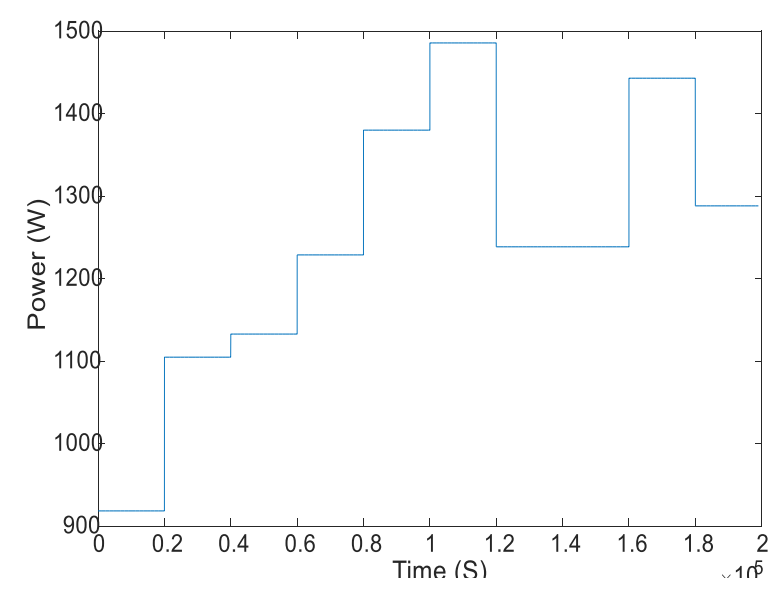

Figure 6. The obtained output power

Table 2. The output values of the TEG modules at the chosen temperature values

\begin{tabular}{ccc}
\hline Maximum and minimum output DC values at the chosen hot side temperature & One TEG module & The used TEG modules \\
\hline Voltage & $0.13-0.44 \mathrm{~V}$ & $60.5-77 \mathrm{~V}$ \\
Current & $0.07-0.25 \mathrm{~A}$ & $15.1-19.4 \mathrm{~A}$ \\
Power & $0.009-0.11 \mathrm{~W}$ & $920-1490 \mathrm{~W}$ \\
\hline
\end{tabular}

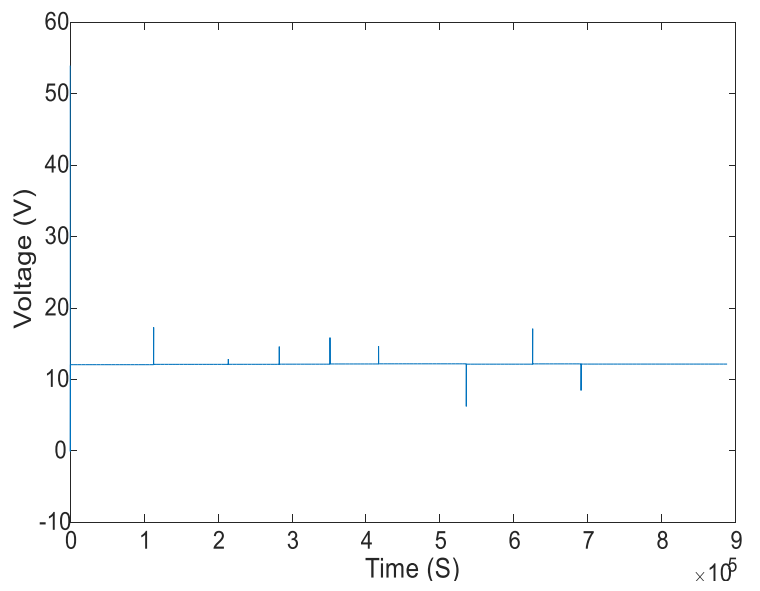

Figure 7. The DC voltage output from the voltage regulator

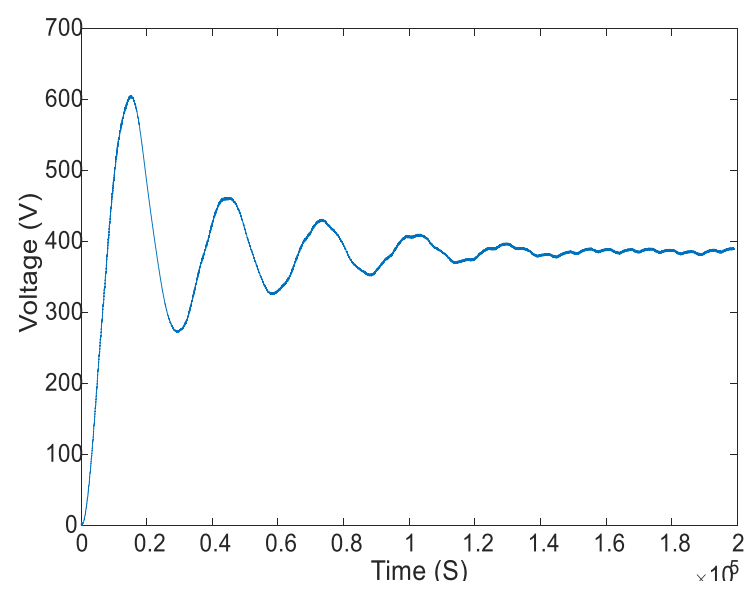

Figure 8 . The output of the voltage boost converter

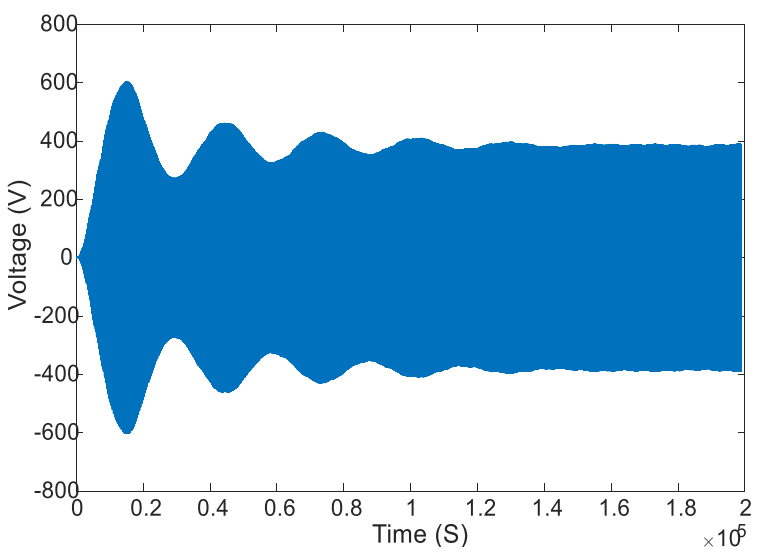

Figure 9. The output of the power inverter 


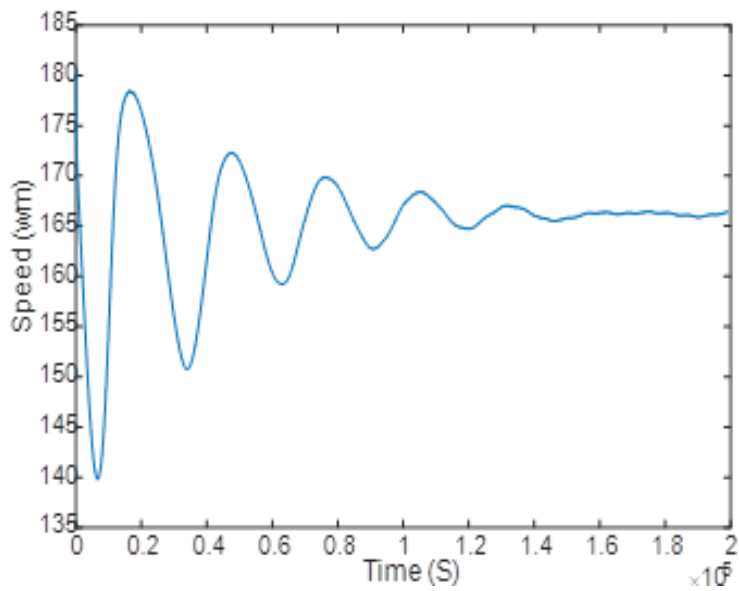

Figure 10. The output AC motor speed

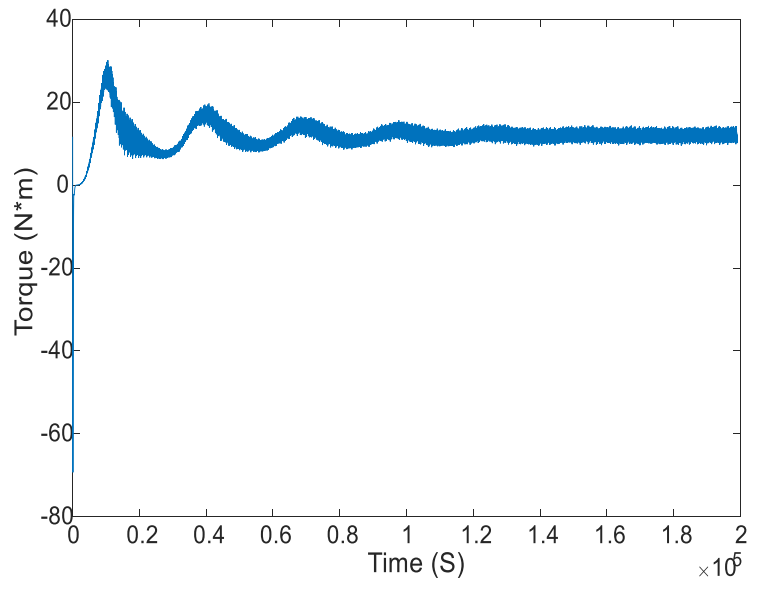

Figure 11. The output AC motor torque

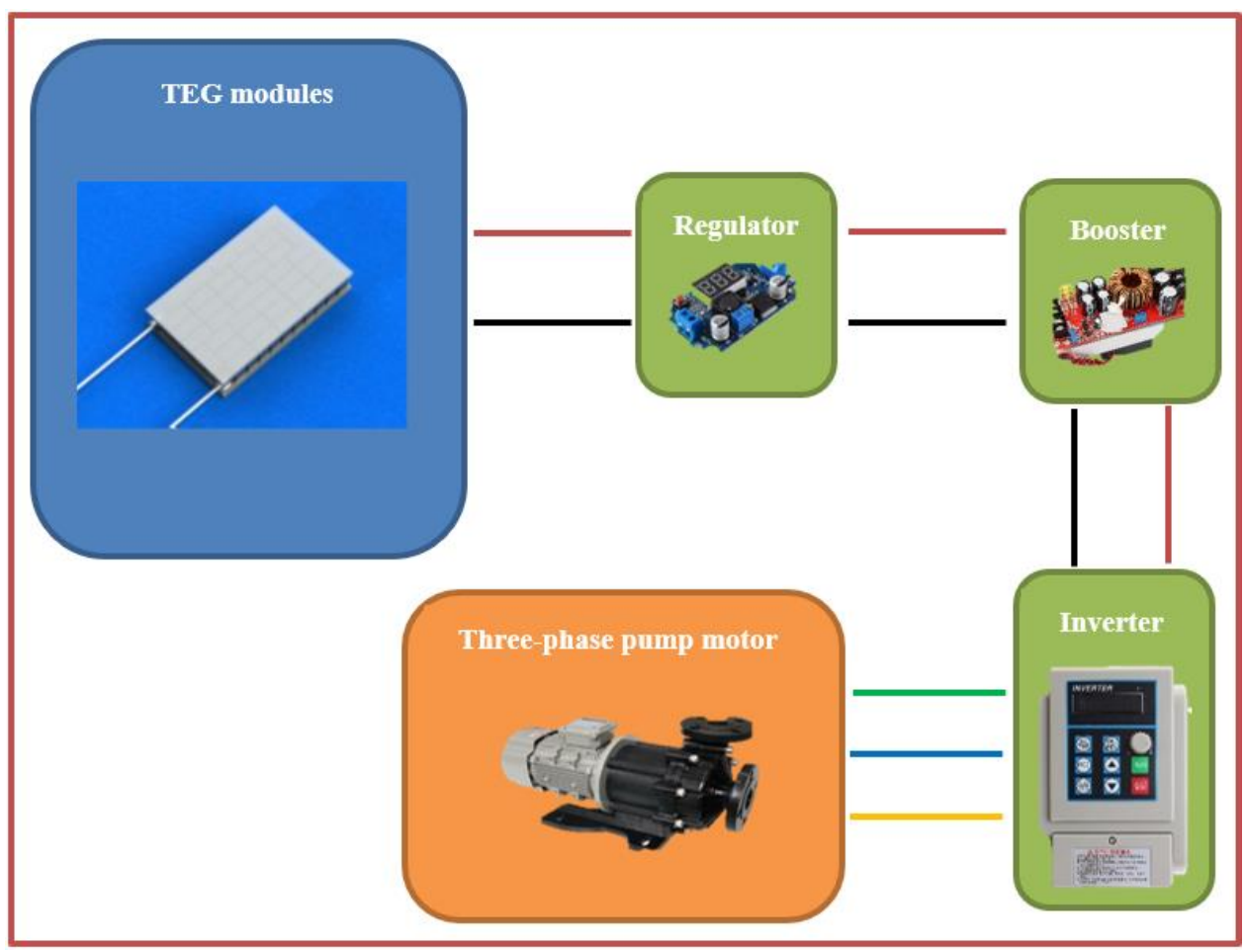

Figure 12. Building the proposed TEG water pumping system

Table 3. Cost analysis of the proposed system

\begin{tabular}{cc}
\hline Component & Approximated cost in USD \\
\hline TEG modules & $\$ 65753$ \\
Voltage regulator & $\$ 26$ \\
Voltage boost converter & $\$ 16$ \\
Power inverter & $\$ 822$ \\
Three-phase motor & $\$ 323$ \\
Total cost & $\$ 66940$ \\
\hline
\end{tabular}

\section{CONCLUSION}

The paper presented a renewable energy power system design for water pumping applications. The system uses 400 TE modules in each of the 15 parallel TEG blocks. The modules are used to operate a threephase AC water pumping motor. Other components that were involved in the system design are DC voltage 
regulator to obtain constant $12 \mathrm{~V} \mathrm{DC}$ voltage, DC voltage boost converter to raise the constant DC voltage to be close to $380 \mathrm{~V}$, and DC to AC three-phase power inverter to obtain $380 \mathrm{~V}$ AC voltage for powering the AC three-phase motor. The proposed renewable energy system was simulated using Simulink to demonstrate the performance of the proposed system under different temperature values. The speed of the AC water pump motor was maintained at constant value close to $166 \mathrm{wm}$ while the toque was maintained at $11.9 \mathrm{Nm}$. The proposed system can be used to provide continuous water supply to isolated or remote areas in Sharjah.

\section{ACKNOWLEDGEMENTS}

The authors wish to acknowledge the support provided by University of Sharjah, UAE.

\section{REFERENCES}

[1] R. Nagaraj, D. Thirugnanamurthy, M. M. Rajput, and B. K. Panigrahib, "Techno-economic analysis of hybrid power system sizing applied to small desalination plants for sustainable operation," International Journal of Sustainable Built Environment, vol. 5, no. 2, pp. 269-276, 2016, doi: 10.1016/j.ijsbe.2016.05.011.

[2] B. Heidary, T. Tavakoli, B. Ghobadian, and R. Roshandel, "Performance Analysis Of Hybrid Solar-Wind Ro-Msf Desalination System," International Resource-Efficient Technologies, vol. 2, pp. 1-16, 2019, doi: 10.18799/24056537/2019/2/184.

[3] M. Aliyu, G. Hassana, S. A. Said, M. U. Siddiqui, A. T. Alawami, and I. M. Elamind, "A review of solar-powered water pumping systems," Renewable and Sustainable Energy Reviews, vol. 87, pp. 61-76, 2018, doi: 10.1016/j.rser.2018.02.010.

[4] P. K. S. Rathore, S. Rathore, R. P. Singh, and S. Agnihotri, "Solar Power Utility Sector in India: Challenges and Opportunities," Renewable and Sustainable Energy Reviews, vol. 81, no. 2, pp. 2703-2713, 2018, doi: 10.1016/j.rser.2017.06.077.

[5] M. B. Hayat, D. Ali, K. C. Monyake, L. Alagha, and N. Ahmed, "Solar Energy-A Look into Power Generation, Challenges, And A Solar-Powered Future," International Journal of Energy Research, vol. 43, no. 3, pp. 1049-1067, 2019, doi: 10.1002/er.4252.

[6] A. Al-Dousari et al., "Solar and Wind Energy: Challenges and Solutions in Desert Regions," Energy, vol. 176, pp. 184-194, 2019, doi: 10.1016/j.energy.2019.03.180.

[7] J. Li, J. K. Ward, J. Tong, L. Collins, and G. Platt, "Machine Learning for Solar Irradiance Forecasting of Photovoltaic System," Renewable energy, vol. 90, pp. 542-553, 2016, doi: 10.1016/j.renene.2015.12.069.

[8] D. Verma, S. Nema, A. M. Shandilya, and S. K. Dash, "Maximum Power Point Tracking (MPPT) Techniques: Recapitulation in Solar Photovoltaic Systems," Renewable and Sustainable Energy Reviews, vol. 54, pp. 1018-1034, 2016, doi: 10.1016/j.rser.2015.10.068.

[9] T.-T. Ma and T.-H. Shr, "Design and Hardware Implementation of a Versatile Photovoltaic Power Generating System," 2013 International Review of Electrical Engineering (IREE), vol. 8, no. 1, pp. 207-215, 2013.

[10] M. Farhat, O. Barambones, and L. Sbita, "A New Maximum Power Point Method Based on a Sliding Mode Approach for Solar Energy Harvesting," Applied energy, vol. 185, no. 2, pp. 1185-1198, 2017, doi: 10.1016/j.apenergy.2016.03.055.

[11] K. Shah, V. Krishnasamy, and S. Neeli, "Sliding mode assisted MPPT technique using quadratic boost converter for solar PV based DC water pumping system," 2017 International Conference on Intelligent Computing and Control (I2C2), 2017, pp. 1-5, doi: 10.1109/I2C2.2017.8321961.

[12] A. Loukriz, M. Haddadia, and S. Messalti, "Simulation and Experimental Design of a New Advanced Variable Step Size Incremental Conductance MPPT Algorithm for PV Systems," ISA transactions, vol. 62, pp. 30-38, 2016, doi: 10.1016/j.isatra.2015.08.006.

[13] S. Tang, Y. Sun, Y. Chen, Y. Zhao, Y. Yang, and W. Szeto, "An Enhanced MPPT Method Combining FractionalOrder and Fuzzy Logic Control," in IEEE Journal of Photovoltaics, vol. 7, no. 2, pp. 640-650, March 2017, doi: 10.1109/JPHOTOV.2017.2649600.

[14] W. G. J. H. M. van Sark, "Feasibility of photovoltaic-Thermoelectric hybrid modules," Applied Energy, vol. 88, no. 8, pp. 2785-2790, 2011, doi: 10.1016/j.apenergy.2011.02.008.

[15] E. Cha'vez-Urbiola, Y. V. Vorobieva, and L. P. Bulat, "Solar hybrid systems with thermoelectric generators," Solar Energy, vol. 86, no. 1, pp. 369-378, 2012, doi: 10.1016/j.solener.2011.10.020.

[16] K. Park et al., "Photovoltaic and thermoelectric devices," Scienctific Reports, vol. 3, no. 1, pp. 1-6, 2013, doi: 10.1038/srep02123.

[17] A. Rezania, D. Sera, and L. A. Rosendahl, "Coupled thermal model of photovoltaic-thermoelectric hybrid panel for sample cities in Europe," Renewable Energy, vol. 99, pp. 127-135, 2016, doi: 10.1016/j.renene.2016.06.045.

[18] E. Yin, Q. Lia, and Y. Xuanab, "One-day performance evaluation of photovoltaic-thermoelectric hybrid system," Energy, vol. 143, no. 15, pp. 337-346, 2018, doi: 10.1016/j.energy.2017.11.011.

[19] M. Shatar et al., "Performance Evaluation of Unconcentrated Photovoltaic-Thermoelectric Generator Hybrid System under Tropical Climate," Sustainability, vol. 11, no. 22, pp. 6192, 2019, doi: 10.3390/su11226192.

[20] B. D. Vick and B. A. Neal, "Analysis of off-grid hybrid wind turbine/solar PV water pumping systems," Solar Energy, vol. 86, no. 5, pp. 1197-1207, 2012, doi: 10.1016/j.solener.2012.01.012. 
[21] B. Bhayo, H. H. Al-Kayiema, and S. I. Gilania, "Assessment of standalone solar PV-Battery system for electricity generation and utilization of excess power for water pumping," Solar Energy, vol. 194, pp.766-776, 2019, doi: 10.1016/j.solener.2019.11.026.

[22] M. Benghanem, K. O. Daffallah, A. A. Joraid, S. N. Alamri, and A. Jaber, "Performances of solar water pumping system using helical pump for a deep well: a case study for Madinah, Saudi Arabia," Energy Conversion and Management, vol. 65, pp. 50-56, 2013, doi: 10.1016/j.enconman.2012.08.013.

[23] W. Obaid, A. Hamid, and C. Ghenai, "Hybrid MPPT Controlled Solar/Wind Power System for Pumping System," 2019 International Conference on Electrical and Computing Technologies and Applications (ICECTA), 2019, pp. 1-4, doi: 10.1109/ICECTA48151.2019.8959772.

[24] W. Obaid, A. Hamid, and C. Ghenai, "Hybrid Solar/Wind/Diesel Power System for Water Pumping Application," 2019 7th International Renewable and Sustainable Energy Conference (IRSEC), 2019, pp. 1-6, doi: 10.1109/IRSEC48032.2019.9078183.

[25] W. Obaid, A. Hamid, and C. Ghenai, "Hybrid Fuel-Cell-Solar Power System Design for Water Pumping Applications with Fuzzy Energy Management and Weather Forecasting," 2020 Advances in Science and Engineering Technology International Conferences (ASET), $2020, \quad$ pp. $1-5$, doi: 10.1109/ASET48392.2020.9118259.

[26] H. L. Tsai, and J. M. Lin, "Model building and simulation of thermoelectric module using Matlab/Simulink," Journal of Electronic Materials, vol. 39, no. 9, p. 2105, 2010.

[27] A. Kane and V. Verma, "Performance enhancement of building integrated photovoltaic module using thermoelectric cooling," International Journal of Renewable Energy Research (IJRER), vol. 3, no. 2, pp. 320-324, 2013.

[28] S. Twaha, J. Zhu, Y. Yan, B. Li, and K. Huang, "Performance analysis of thermoelectric generator using dc-dc converter with incremental conductance based maximum power point tracking," Energy for Sustainable Development, vol. 37, pp. 86-98, 2017, doi: 10.1016/j.esd.2017.01.003. 